\title{
Review
}

\section{Dance of plants with circadian clock}

\author{
Kanae Niinuma, Mayu Nakagawa, Martin Calvino, Tsuyoshi Mizoguchi* \\ Institute of Biological Sciences, University of Tsukuba, Tennodai 1-1-1, Tsukuba, Ibaraki 305-8572, Japan \\ *e-mail: mizoguchi@gene.tsukuba.ac.jpＴel: +81-298-53-6005Ｆax: +81-298-53-7723
}

Received December 24, 2006; accepted January 12, 2007 (Edited by M. Sekine)

\begin{abstract}
Endogenous oscillator called circadian clock controls many physiological aspects. Since the identification of LATE ELONGATED HYPOCOTYL (LHY) and CIRCADIAN CLOCK ASSOCIATED 1 (CCA1) genes as the 1st candidates for clock components in plants, many clock-associated genes have been identified in Arabidopsis and other plant species. The 1st negative feedback model composed of LHY, CCA1 and TIMING OF CAB EXPRESSION 1 (TOC1) has recently been modified based on possible functions of new players. Photoperiodic flowering is controlled by clock and our knowledge on molecular mechanisms underlying the clock-controlled process has much advanced in this decade. Recently, we have started to understand how the clock regulates organ movements and elongations in a model plant, Arabidopsis. In this short review, i) a history of construction of models on circadian rhythms in Arabidopsis, ii) modified models on circadian system in Arabidopsis, iii) recent progress on understanding molecular mechanisms underlying organ movements controlled by a circadian clock and iv) advantages of using tomato as a model system for chronobiology are summarized and discussed.
\end{abstract}

Key words: Circadian clock, Circumnutation, LATE ELONGATED HYPOCOTYL (LHY), Micro-Tom, PSEUDO RESPONSE-REGULATOR (PRR).

Circadian clock is an endogenous oscillator with an approximate period of $24 \mathrm{~h}$ that can be entrained to the exact period of daily oscillations in light and temperature (Dunlap 1999). This process enables an organism to phase its biological activities to the correct time of day. The circadian rhythm has been reported in many processes in various organisms (Dunlap 1999) from cyanobacteria, fungi and plants to humans. The first report about a circadian rhythm is in plant leaf movement. In 1729, De Mairan, a French astronomer, found that leaf movement in Mimosa pudica which had been already known to open (horizontal) during day and close (vertical) during night persisted even after transfer to continuous dark (DD) condition. This suggests that the leaf movements were not simple response to the light and were controlled by the endogenous circadian clock.

Since the $1^{\text {st }}$ report on the clock-controlled phenomena, our knowledge on molecular mechanisms of the circadian clock has much advanced. In this review, a short history of models explaining the circadian rhythms in plants is shown in the $1^{\text {st }}$ and $2^{\text {nd }}$ sections. Recent progress on characterization of organ movements, classical but still mysterious and uncovered outputs controlled by the circadian clock in plants are shown in the $3^{\text {rd }}$ section. Finally, advantages to use tomatoes for studies on circadian rhythms are discussed in more detail in the $4^{\text {th }}$ section.

\section{Negative feedback models at the early stage of the Arabidopsis clock studies}

Two Myb-related genes, LATE ELONGATED HYPOCOTYL (LHY) and CIRCADIAN CLOCK ASSOCIATED 1 (CCA1), have been shown to be closely associated with clock function in Arabidopsis (Schaffer et al. 1998; Wang and Tobin 1998). Expression of LHY and CCAI oscillates with a circadian rhythm. Over-expression of either LHY or CCAl causes arrhythmic expression of clock-controlled genes $(C C G s)$ and reduction of their own expression. Lack of CCA1 in a T-DNA insertion mutant line (ccal-1) shortened the period of the rhythm in the expression of LHY and other CCGs (Green and Tobin 1999).

TOCl gene is also a part of central oscillator function in Arabidopsis (Millar et al. 1995). The tocl mutant was initially identified in a screen for mutations that disrupt the circadian-clock-controlled pattern of expression of the gene encoding the chlorophyll $a / b$ binding protein $(\mathrm{CAB})$ by using a $C A B$ promoter fusion to luciferase (luc). In tocl mutants, circadian clock regulation still occurs, but the circadian-clock-controlled peaks in gene expression occur approximately every 21 hours instead of every 24 hours. Leaf movement and stomatal conductance rhythms were similarly $\sim 3$ hours shorter than wild type (Somers et al. 1998). These results 
indicate that TOC1 plays pivotal roles in a variety of clock-controlled processes throughout development in Arabidopsis. TOC1 gene has been identified by a mapbased cloning and encodes a protein with a response regulator domain and a CCT motif that is conserved in CONSTANS (CO), CONSTANS LIKE (COL) and TOC1 (Putterill et al. 1995; Strayer et al. 2000; Ledger et al. 2001).

Histidine-to-aspartate (His-Asp) phosphorelay (or two-component) systems are very common signal transduction mechanisms that are implicated in a wide variety of cellular responses to environmental stimuli (Appleby et al. 1996). A His-to-Asp phosphorelay system consists of two or more common signal transducers, a sensor exhibiting His-kinase activity, a response regulator containing a phospho-accepting Asp in its receiver domain and a His-containing phosphotransmitter (HPt) (Parkinson and Kofoid 1992, Mizuno 1998). The TOC1 gene was also identified as PSEUDO-RESPONSE REGULATOR 1 (PRRl) gene during the course of systematic studies of the His-to-Asp phosphorelay system in Arabidopsis (Matsushika et al. 2000).

The TOC1/PRR1 mRNA oscillates with high hhamplitude in wild-type plants in constant light (LL) (Matsushika et al. 2000, Strayer et al. 2000). The TOC1/PRR1 mRNA level is constant in both LHY-1 (LHY-OX) and CCA1-OX plants under the same light condition (Alabadí et al. 2001, Figure 1B). High and constant expression levels of either $L H Y$ or $C C A 1$ result in low and constant levels of TOC1/PRR1 transcript in LL. This suggests that LHY and CCA1 are negative regulators of TOC1/PRR1. This idea is supported by the fact that TOC1/PRR1 transcript oscillates 12 hours out of phase with both $L H Y$ and $C C A 1$ transcripts in wild-type plants (Strayer et al. 2000). Moreover, both LHY and CCA1 bind to a region in the TOC1/PRR1 promoter that is critical for its clock regulation, suggesting that both LHY and CCA1 may act directly to negatively regulate TOC1/PRR1 expression (Alabadí et al. 2001) (Figure $1 \mathrm{~B})$.

We have isolated three loss-of-function alleles of $L H Y$ (lhy-11, lhy-12 and lhy-13), and demonstrate that these mutations shorten the period of the $C C G$ expressions and leaf movements under continuous conditions (Mizoguchi et al. 2002). A similar short period phenotype was previously shown for ccal-1 null mutant (Green and Tobin 1999). We constructed lhy ccal double mutants and these plants lost free-running rhythms in $C C G$ expressions after a few cycles in LL (Mizoguchi et al. 2002). Therefore LHY and CCA1 have partially redundant functions that are essential for the maintenance of circadian rhythmicity in LL. In addition, under light/dark cycles the lhy ccal double mutants show dramatic shifts earlier in the phase of expression of
CCGs that normally peak in the evening. These CCGs include GIGANTEA $(G I)$ and TOCI/PRRI that are associated with the generation of circadian rhythms, and are required for peak expression levels of $L H Y$ and CCA1 (Mizoguchi et al. 2002).

Plants lacking $C C A 1$ and with $L H Y$ function strongly reduced (ccal-1 lhy-R) were generated using doublestranded RNA interference (RNAi) technology (Alabadí et al. 2002). These plants were unable to maintain sustained oscillations of $C C G$ expressions and leaf movements in LL. These phenotypes are quite similar to those seen in lhy ccal double knockout mutants (Mizoguchi et al. 2002). The ccal-1 lhy-R disrupted circadian rhythms not only in LL but in DD using bioluminescence analysis of the COLD, CIRCADIAN RHYTHM 2 (CCR2): luc reporter (Alabadí et al. 2002). Results obtained by two independent groups clearly show that both LHY and CCA1 are required for maintenance of circadian rhythms under continuous conditions.

Regulations between $L H Y$ and $C C A 1$ that peak at dawn, and TOC1/PRRI and GI that peak in the evening appear to be reciprocal. Loss-of-function mutation of tocl (tocl-2) reduced peak levels of LHY and CCA1 expressions (Alabadí et al. 2001) (Figure 1B). The $g i$ mutation had similar effect on the high amplitude of oscillation for both LHY and CCAl expressions (Mizoguchi et al. 2002). These results suggest that TOC1/PRR1 and GI appear to function to control gene expression of $L H Y$ and $C C A 1$ in a positive regulatory loop (Figure 1C).

Over-expression of TOC1/PRR1 dampened the freerunning robust rhythms of $L H Y$ and CCAI (Matsushika et al. 2002). In particular, rhythmic expression of $G I$ gene was completely suppressed in TOC1/PRR1-OX plants under LL. Based on results obtained from both gain-of-function mutants (lhy-1, CCA1-OX and TOC1/ PRRI-OX) and loss-of-function mutants (lhy, ccal, lhy ccal, tocl and gi), a negative feedback model composed of these clock components in Arabidopsis was proposed (Figure 1C). In this model, $L H Y$ and CCAl which peak at dawn negatively regulate their own expression and also expressions of TOC1/PRR1 and GI. On the other hand, TOC1/PRRI and GI genes peak in the evening and appear to function as positive regulators of $L H Y$ and CCA1.

\section{Circadian clock genes and modified models on circadian system in Arabidopsis}

More than 10 Arabidopsis genes that are highly associated with circadian clock functions have been isolated. Recently, a triple mutant of $p r r 9, \operatorname{prr} 7$ and $p r r 5$, has been characterized and phenotypes of the triple mutant plants have been compared to those of double 
mutants, prr7 prr5, prr9 prr7 and prr9 prr5 (Nakamichi et al. 2005) (Figure 1E). Also novel classes of proteins such as EARLY FLOWERING 4 (ELF4) (Doyle et al. 2002, Figure 1D) and PHYTOCLOCK1(PCL1)/LUX ARRHYTHMO (LUX) (Hazen et al. 2005; Onai and Ishiura 2005) (Figure 1F) as candidates for clock genes have been isolated in Arabidopsis. GI has been reconsidered as a clock associated gene (Locke et al. 2005; Mizoguchi et al. 2005) (Figure 1D, G). A current view of a modified clock model composed of PRRs, PCL/LUX and GI as well as LHY, CCA1 and TOC1 appears to be quite complex (Figure 1H). We should modify it again when we will identify new players for the circadian clock in Arabidopsis.

\section{Organ movement as one of the clock- controlled outputs in plants}

Photoperiodic flowering, mRNA stability (Lidder et al. 2005), starch degradation and maltose metabolism ( $\mathrm{Lu}$ et al. 2005), photosynthesis (Dodd et al. 2005a), $\mathrm{Ca}^{2+}$ level (Dodd et al. 2005b reviewed) and organ movements (Niinuma et al. 2005; Someya et al. 2006) have been shown to be controlled by the circadian clock. Among these, the regulation of flowering time has been well characterized and summarized in other recent reviews (Hayama and Coupland, 2003; Salome and McClung, 2004; Calvino et al. 2005; Mizoguchi et al. 2006). In this section, recent progress on the characterization of the organ movements such as leaf movements, stem elongation and circumnutation are summarized (Figure 2A).

\section{Leaf movements in plants with or without pulvini}

At least two types of leaf movements have been reported. One is the leaf movement caused with pulvinus, the organ on the bottom part of the leaf. For example, legumes have pulvini and the leaf movement system with pulvinus has been investigated in Phaseolus coccineus, Phaseolus vulgaris, Samenea saman and Albizza lophanta (Engelmann and Johnsson 1998). Changes of turgor volume in the upper and lower parts of pulvinus result in the leaf movements and the upper and lower parts are called flexor and extensor, respectively (Satter et al. 1974). The extensor and flexor cells swell and shrink, respectively, during closure, whereas the extensor and flexor cells shrink and swell, respectively, during opening (Coté 1995). Circadian rhythm of leaf movement, which usually opens during day and closes during night, is mediated by circadian volume changes in the extensor and flexor. Satter and Morse (1990) detached pulvini from the plants and removed their leaves. The pulvini still maintained to bend rhythmically under DD with a period of approximate 24 hours. Moreover, the circadian rhythm of volume change was also observed in the protoplasts isolated from the extensor and flexor cells, similar to in those of pulvinar cells in situ (Mayer and Fisher 1994). These results suggest that the cells in extensor and flexor have own endogenous circadian clocks.

Ion efflux such as $\mathrm{K}^{+}, \mathrm{H}^{+}, \mathrm{Cl}^{-}$, malate, and other small organic anions affects the turgor changes (Satter et al. 1974; Kiyosawa et al. 1979). $\mathrm{K}^{+}$and main counterion to $\mathrm{K}^{+}, \mathrm{Cl}^{-}$, increase in the swelling cells and simultaneously decrease in the shrinking cells (Satter and Galston 1981; Satter et al. 1988). The $\mathrm{K}^{+}$permeability is controlled by light (Lowen and Satter 1989, Kim et al. 1992; Suh et al. 2000) and the circadian clock (Kim et al. 1993). The extensor and flexor cells in $S$. samae have four genes encoding $\mathrm{K}^{+}$channels (Moshelion et al. 2002a). Expression of the four $\mathrm{K}^{+}$channel genes show diurnal rhythms under light and dark cycles and three of them are controlled by circadian clock.

Second class of leaf movements is observed in plants such as Arabidopsis and these plants lack the pulvinus. Although most of plants do not have the special motor organs pulvini, they show leaf movements that are under the control of circadian rhythms (Engelmann et al. 1992). This change of leaf position is caused by differential growth in its petiole between upper and lower sides (Engelmann and Johnsson 1998) and is also reported to be related with cell division and elongation (Poethig and Sussex 1985). Aquaporin, a water channel, is suggested to be involved in the rhythmic leaf movement with puilvini (Moshelion et al. 2002b). Expression of Samanea saman Aquaporin 2 (SsAQP2) is restricted to the movement-associated parts of the leaf and is cotrolled by circadian clock.

Leaf movements have been used as rhythmic markers in plants for chronobiology. Leaf movements are usually recorded from the side to obtain three circadian parameters, period, phase and amplitude. The amplitude is the vertical distance between the highest position and the lowest position of leaf during one cycle. The period is the duration for one up-and-down movement of a leaf. The phase is the time when the leaves are in the highest position. Plants with short and thick petioles, for example Arabidopsis plants with erecta (er) mutation, showed normal period and phase in the leaf movements, but lower amplitude compared to that of wild-type plants (Swarup et al. 1999). We have to interpret experimental results carefully, when we adapt the leaf movement as a rhythmic marker, because leaf movement is affected by morphology of plants used for the experiments.

\section{Hypocotyl and inflorescence stem elongations}

Elongation rates of hypocotyl and infloresence stem oscillate with a circadian rhythm (Dowson-Day et al. 1999; Jouve et al. 1998). Hypocotyl is usually composed of approximately 22 cells at longitude axis and its 
elongation depends on cell elongation (Gendreau et al. 1997). By contrast, stem elongation is associated with both cell division in the shoot apical meristem and cell elongation.

Elongation is influenced by plant hormones auxin, gibberellins, brassinosteroids, cytokinins, abscisic acid and ethylene, positively and negatively (Chory et al. 1944, Creelman and Mullet 1997; Kende and Zeevaart 1997; McGrath and Ecker 1998). For example, Indole-3acetic acid (IAA) plays an important role in circadian rhythm of stem elongation. Endogenous levels of IAA and IAA-aspartate that is biologically inactive until conjugate is cleaved off fluctuated with circadian period (Jouve et al. 1999). Decapitation suppressed elongation and circadian rhthmicity of the inflorescence node of Arabidopsis. Application of IAA but not IAA-aspartate after decapitation re-established the elongation and its circadian rhythmicity in the first inflorescence node of Arabidopsis (Jouve et al. 1999). Circadian rhythm of free IAA level may be resulted from the inter-conversion between IAA and its conjugates (Hangarter and Good 1981; Kleczkowski and Schell 1995). IAA metabolism is thought to be essential for circadian rhythmicity of elongation of the stem and hypocotyl in Arabidopsis (Jouve et al. 1999). Ethylene is also known to influence cell elongation. However, rhythmic elongation does not require the rhythmic production of ethylene, because hypocotyl elongation in ethylene mutants such as ethylene-overproducer 2 (eto2), ethylene-insensitive 4 (ein4) and ethylene-resistant 1 (etrl), showed circadian rhythms (Thain et al. 2004).

In Arabidopsis, several mutants lacking circadian clock-associated genes have altered hypocotyl lengths (Schaffer et al. 1998; Wang and Tobin 1998; Somers et al. 2000; Nozue and Maloof 2006), raising a possibility that these hypocotyl phenotypes are caused by altered circadian rhythms. EARLY FLOWERING 3 (ELF3) plays a key role in gating light signals to the circadian clock (Hicks et al. 1996; McWatters et al. 2000; Covington et al. 2001; Liu et al. 2001). The elf3 mutants are conditionally arrhythmic in various circadian outputs under LL (Zagotta et al. 1992; Hicks et al. 1996). The elf3 mutant plants also show arrhythmic hypocotyl elongation (Dowson-Day et al. 1999). The arrhythmicity in elf3 appears to be caused by abolishing the growth arrest during subjective dawn. Therefore, loss-offunction of ELF3 makes longer hypocotyls than wildtype plants (Dowson-Day et al. 1999).

Figure 1. A brief history of the hypothetical models of circadian clock. (A) The initial model showing the core feedback loop central to circadian oscillators (modified from Dunlap 1999). This model provides a view of what some of the common elements might be in the logic underlying the assembly of circadian oscillators. In this model, the positive element $\mathrm{Y}$ acts as a transcriptional activator to induce clock gene (X) expression. The protein products (negative element) of the clock gene $\mathrm{X}$, in turn, block the action of the positive element, thus indirectly repressing their own expression. (B) The initial negative feedback model of Arabidopsis clock composed of LHY, CCA1 and TOC1/PRR1 (modified from Alabadi et al. 2001). This model is mainly based on both LHY and CCA1 proteins bind to a region in the TOC1 promotor and genes expression patterns as following: Light activates $L H Y$ and CCAI expression at dawn. LHY and CCA1 activate $C A B$ expression and possibly other genes with a phase similar to $C A B$. LHY and CCA1 simultaneously repress $T O C 1$ and other evening genes. The reduction of $L H Y$ and $C C A 1$ expression levels during the day allows TOC1 transcript levels to rise and reach maximum levels toward the end of the day, when $L H Y$ and $C C A 1$ expression levels are lowest. TOC1 appears to participate in the positive regulation of $L H Y$ and $C C A 1$ expression, which reach maximum levels at dawn. (C) A model showing relations among LHY, CCA1, TOC1, GI and other evening phased genes to control the Arabidopsis clock (modified from Mizoguchi et al. 2002). $L H Y$ and $C C A 1$ transcription rises early in the day, which may reflect a direct response to light as well as circadian regulation. The model proposes that $L H Y$ and $C C A 1$ genes (red) act as negative elements that repress $G I$ and TOCI (blue) expression and feedback to repress their own expression. As the expression of $L H Y$ and CCAI subsides, the levels of GI and TOCI mRNA rise and eventually peak in the evening. The GI and TOC1 genes promote expression of $L H Y$ and CCA1. (D) The modified clock model showing the dual roles of GI in acting within the circadian clock to regulate period length and circadian phase, while also more directly promoting expression of a circadian clock output pathway that includes $C O$ and $F T$ and promotes flowering (modified from Mizoguchi et al. 2005). GI, TOC1, and ELF4 all promote LHY and CCA1 expression. The flowering pathway is one of many output pathways controlled by the circadian clock, and three other pathways expressed at different times of the day are illustrated. Main loop is shown in pink. (E) The modified clock model based on multi-loops composed of not only LHY, CCA1 and TOC1/PRR1 but also PRR9, PRR7 and PRR5 (modified from Mizuno and Nakamichi 2005). This model supposes that the PRR9/PRR7/PRR5 circuitry interlocks with the main loop (pink line) in such a way that the PRR9/PRR7/PRR5 circuitry forms two other positive/negative loops (green and blue lines). The analysis of the prr 9 prr 7 and the $\operatorname{prr} 7$ prr 5 double mutants under temperature cycle suggested that the multi-loop clock can also entrained by temperature cycle. TOC1 interacts with certain bHLH factors including PIF3/4 (PHYTOCHROME INTERACTING FACTOR 3 and 4) and four other homologous bHLH factors, PIL1/2/5/6 (PIF3-LIKE 1/2/5/6). Two PIFs in turn interact with phyB. (F) The modified multi-loop model including new players PCL/LUX and ELF4 (modified from Onai and Ishiura 2005). pcll and elf4 mutations caused arrhythmia in multiple circadian outputs (Onai and Ishiura 2005). elf4 mutation disrupted rhythmic CCA1 expression. In this model, PCL1 is proposed to down-regulate mRNA levels of GI, TOC1, ELF4 and PCL1 itself. Unidentified factors $\mathrm{X}$ is proposed to activate $L H Y$ and $C C A 1$, and $\mathrm{Y}$ and $\mathrm{Z}$ repress $T O C 1$ and ELF4, respectively, in this model. (G) The two-loops model based on computer-simulation (modified from Locke et al. 2005). This model proposes that each loop may receive input signals from light, and that each loop may include a hypothetical component ( $\mathrm{X}$ and $\mathrm{Y}$ ) that had not been explicitly identified (Locke et al. 2005). Analysis of the model predicted the properties of these components, including an acute light induction at dawn that is rapidly repressed by LHY and CCA1. TOC1 is activated by light indirectly via hypothetical gene Y. Y activates TOC1 transcription and both LHY and TOC1 repress Y transcription, forming a second feedback loop. Recently, GI has been proposed to be a strong candidate for X (Locke et al. 2006) and also the threeloops models with PRR9 and PRR7 in the 3rd loop have been reported (Locke et al. 2006, Zeilinger et al. 2006). (H) One of the current views of the Arabidopsis clock composed of multi-loops. LHY, CCA1, TOC1/PRR1, PRR9, PRR7, PRR5, PCL/LUX, GI and ELF4 are included in this model. Pink lines represent a core-loop. Asterisks $\left(^{*}\right)$ indicate that LHY/CCA1 proteins directly bind promoters of TOC1 (Alabadi et al. 2001) and LUX/PCL1 (Hazen et al. 2005). 
A

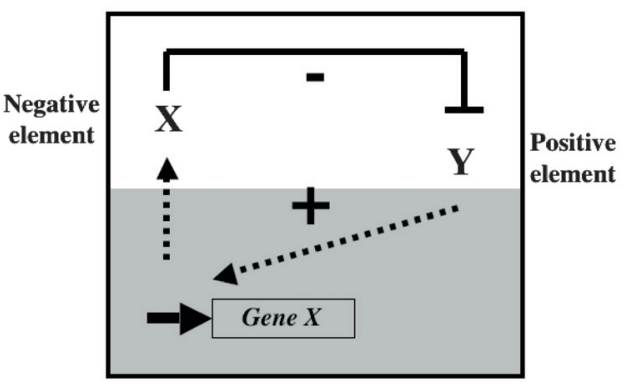

(Dunlap 1999)

C
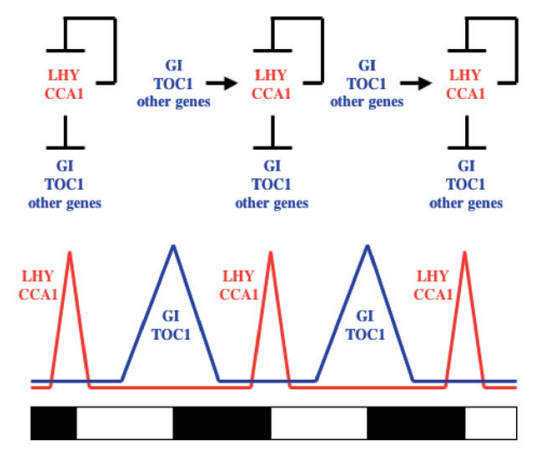

(Mizoguchi et al. 2002)

E

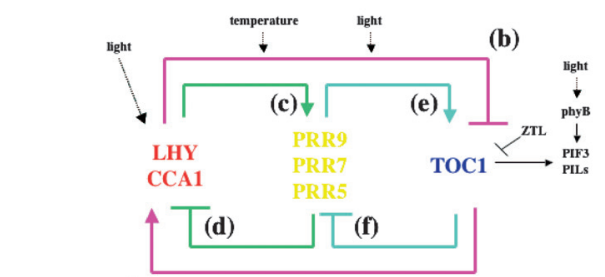

(a)

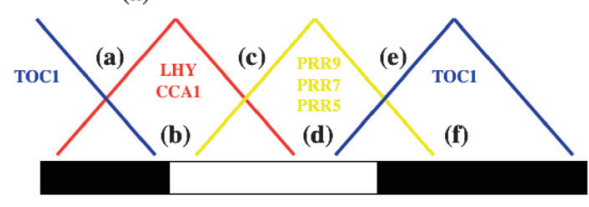

(Mizuno \& Nakamichi 2005)

G

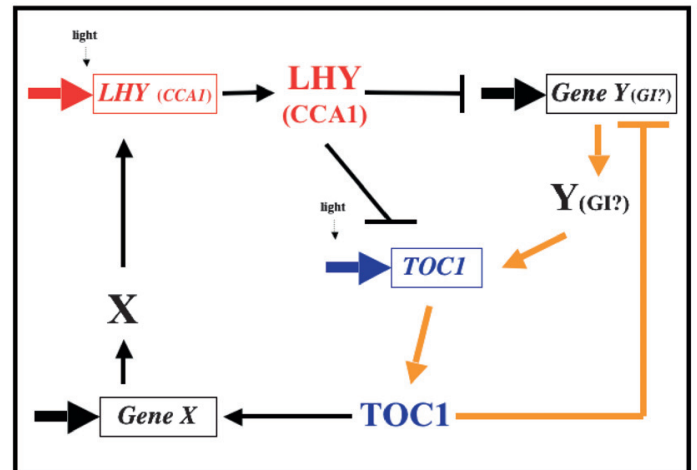

(Locke et al. 2005)
B

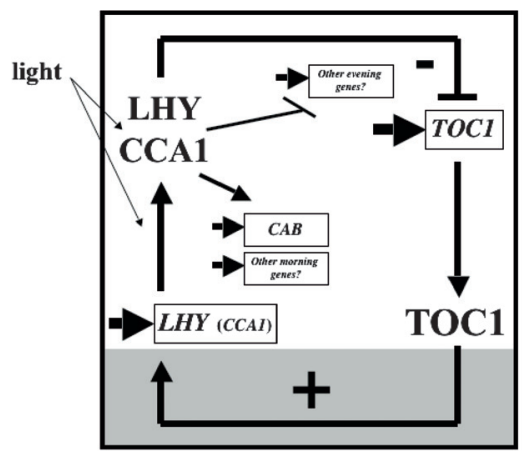

(Alabadi et al. 2001)

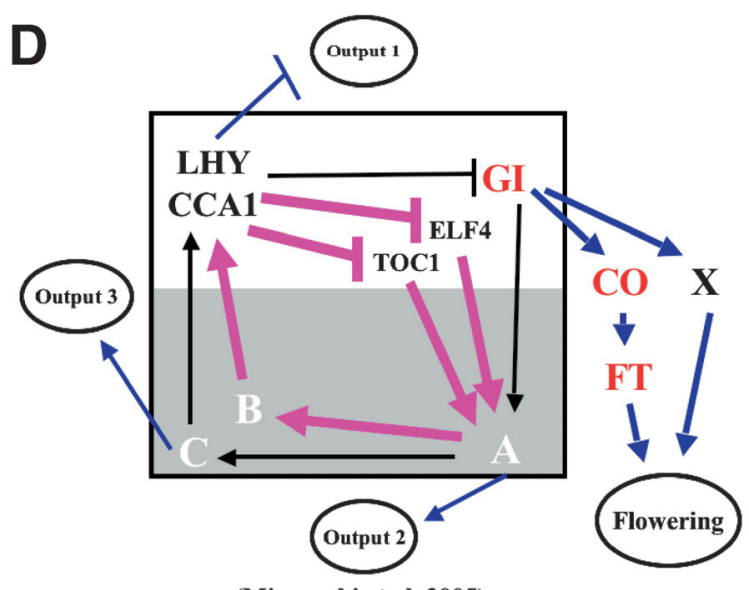

(Mizoguchi et al. 2005)

F

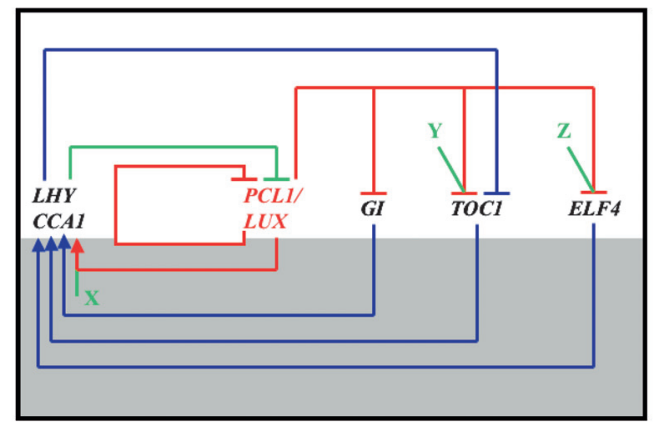

(Onai \& Ishiura 2005)

$\mathrm{H}$

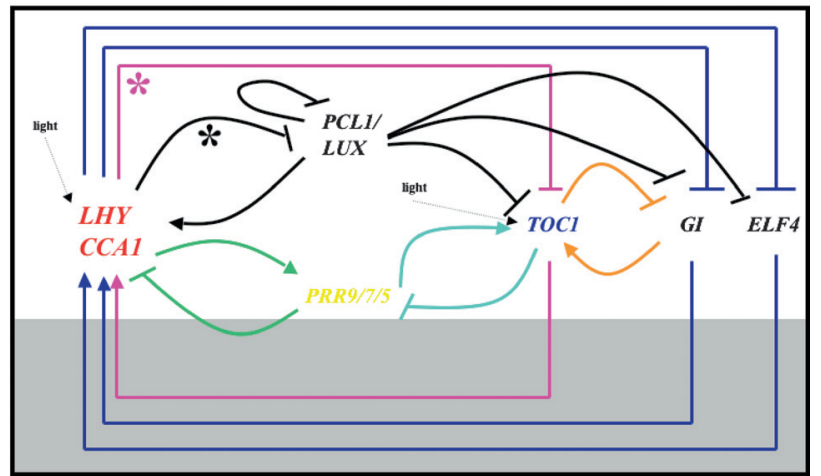


A
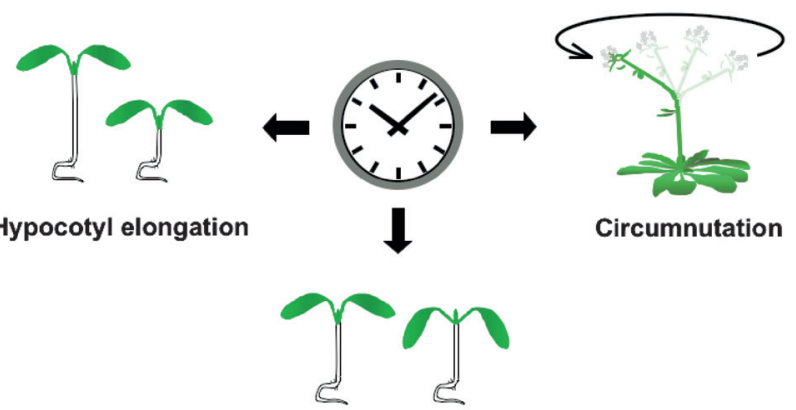

Leaf movement

B

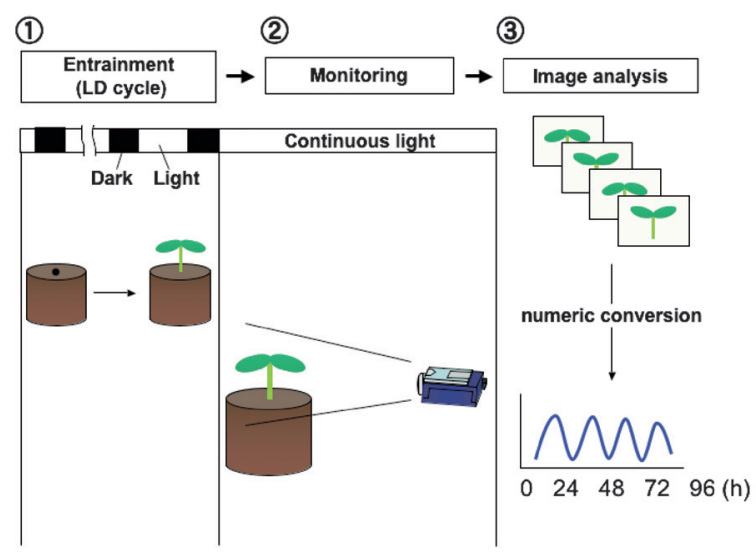

C

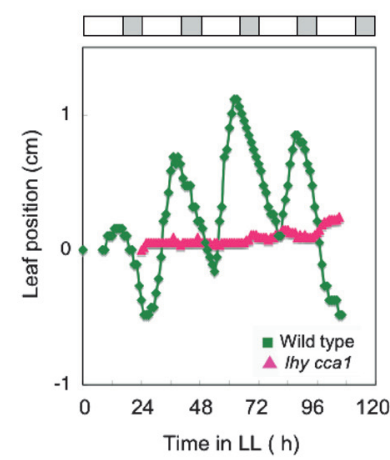

D

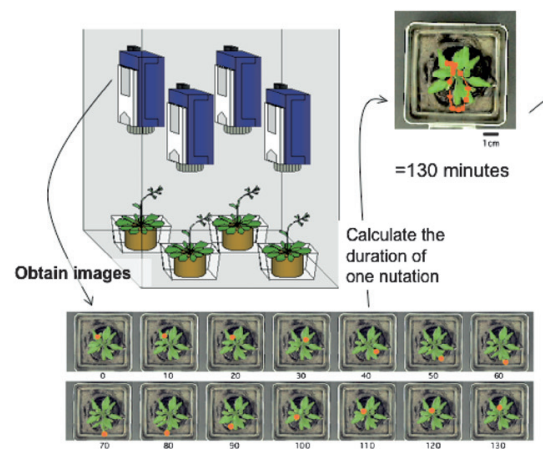

Numeric conversion

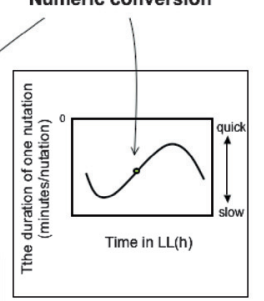

E

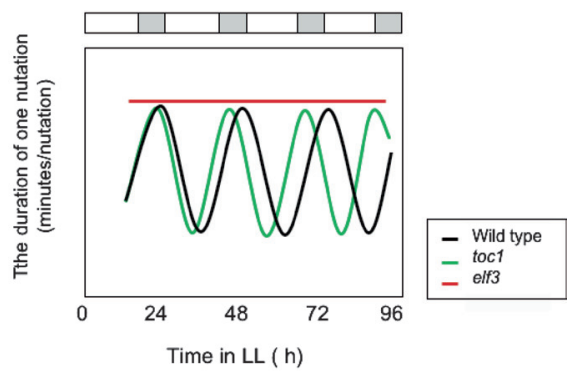

Figure 2. Organ movements controlled by circadian clock in plants. (A) Circadian clock controls various organ movements including hypocotyl elongation, leaf movement and circumnutation. (B) A procedure of monitoring circadian rhythms of leaf movements. At first, plants were grown under LD conditions and monitored their leaf movements after transfer to continuous condition. The movement of the leaf tips was monitored under LL, from above with a video camera (DCR-TRV30, Sony Corporation, Tokyo, Japan). Data were recorded at 5 min. intervals for several days. The data was obtained by numeric conversion with the movies. (C) Circadian rhythms of leaf movements in Arabidopsis wild-type (Ler) and a clock mutant, lhy ccal, under LL. The rhythms were monitored as described in (B). Open and gray bars along the horizontal axis represent subjective day and subjective night periods, respectively. These are measured in hours after the start of the LL treatment (Time in LL). (D) Acquisition of circumnutation data of Arabidopsis. The images were obtained at $5 \mathrm{~min}$. intervals, and data at $10 \mathrm{~min}$. intervals are shown. The coordinates of the inflorescence stem tip (-) were analyzed by the NIH image program (National Institutes of Health, Bethesda, MD, USA) (ref). The duration of one nutation was estimated at $130 \mathrm{~min}$. in this case. (E) A schematic representation of arrhythmic and short period of circumnutation of influorescence stems in elf3 and tocl, respectively. The modulation of circumnutation speed in elf3 (red), tocl (green) and wild-type (black) plants were monitored in LL as shown in (D). Time in LL shows hours after transfer of the plants to LL. Open and dark boxes represent subjective day and subjective night, respectively. 


\section{Circumnutation}

Circumnutations are revolving movements of plant elongating organs, which result from helical growth (Brown 1993) and partly reversible length variations occurring in the cells of the moving part of the organ (Carré et al. 1998). The circumnutating organ tip described pendulum-like, elliptical, or circular pattern (Melin 1975a; Melin 1975b). It usually takes 1 to $5 \mathrm{~h}$ to make one nutation (Lubkin 1994). Although it had been predicted, it was not proven clearly for a long time that the rotation movement showed circadian rhythm or not (Niinuma et al. 2005). This is mainly because the circumnutation is a complicated integration of physiological phenomena. In the cells of the bending zone of circumnutating organ, partly reversible length variations (Carré et al. 1998) are associated with differences of turgor and ion concentration (Lubkin 1994). The circumnutating organ has areas with rhythmically changing cell volumes that have been shown to move around the organ (Millet et al. 1988). Moreover, circumnutation is variable in character according to the plant species, the organ, or even on certain individual traits such as the age of the plant (Baillaud 1962; Darwin and Darwin 1880; Vanden Dressche 2000). Circumnutation is strongly affected by external stimuli such as temperature, light intensity, and mechanical stress (Anderson-Bernadas et al. 1997; Someya et al. 2006).

Characterization of clock mutants, elf3 and toc1 demonstrated that circumnutation is one of the outputs controlled by circadian clock (Niinuma et al. 2005). The modulation of circumnutation speed in inflorescence stem of wild-type is rhythmic with the phases of highest and lowest speed at subjective dawn and dusk, respectively (Figure 2D, E). The tocl mutation shortened the period of the circadian rhythm of the downstream events (Somers et al. 1998). In circumnutation, the tocl1 mutant has a shorter period length compared to that of wild-type and elf3 mutation seems to show constant nutation speed and abolish the rhythm of modulation of circumnutation speed, consistent with previous reports (Figure 2E, Niinuma et al. 2005).

Circumnutation is observed in elongating organ. Elongation rate of stem and hypocotyls is under the control of circadian rhythms (Jouve et al. 1998; DowsonDay et al. 1999), as described in section "Hypocotyl and inflorescence stem elongations". Highest speed of circumnutation and growth arrest occurred at subjective dusk and lowest speed of circumnutation and maximal elongation rate at subjective dawn, respectively (Niinuma et al. 2005). These results suggest that there may be some relationships between speed of circumnutation and elongation rate. Alternatively, speed of circumnutation and elongation rate may be two independent outputs controlled by the circadian clock. In elf 3 mutant, constant and relatively high speed of cicumnutation and elongation rate persisted in LL (Niinuma et al. 2005). These results support the latter idea that circumnutation and elongation are controlled independently by the clock.

\section{Tomato as a model system for chronobiology}

Advantages to use the Solanum lycopersicum cv. MicroTom are often discussed in this issue. We think that the Micro-Tom is a good model plant for comparative genetics on connection between circadian clock and the photoperiodic flowering (Mizoguchi et al. 2007, this issue). Photoperiodic flowering responses of the long day (LD) (Arabidopsis), short day (SD) (rice) and day-neutral (DN) plants (tomato) are shown in Figure 3E. Tight connection between circadian clock and the photoperiodic flowering is shown in a facultative LD plant, Arabidopsis (Mizoguchi et al. 2006; Mizoguchi et al. 2007, this issue). Several processes, however, have been reported to be controlled by circadian clock in tomatoes (Samach et al. 2007, this issue). For examples, circadian clock controls leaf movement of plants. Although Arabidopsis shows a robust oscillation of leaf movement (Figure 2C), Arabidopsis is a small plant and therefore to follow the rhythm of this plant species is rather difficult. Seedlings of the Micro-Tom are much larger than those of Arabidopsis and to follow and monitor the rhythm of Micro-Tom are easier than those of Arabidopsis (Figure 3A).

We observed and analyzed a circadian rhythm of leaf movement of the Micro-Tom by using digital video (Figure 3A, B). LHY and GI play key roles in the control of the photoperiodic flowering and circadian rhythms in Arabidopsis (Mizoguchi et al. 2002; Mizoguchi et al. 2005; Locke et al. 2006; Mizoguchi et al. 2006). The Micro-Tom has genes related to the Arabidopsis LHY and $G I$ and the expression of them showed similar daily and circadian rhythms to those of Arabidopsis (Figure 3C, D) This suggests that these genes may also be involved in the regulation of circadian rhythms in tomato. Although genes related to the key factors of the photoperiodic flowering in Arabidopsis such as LHY, CCA1, GI, CO and FT (FLOWERING LOCUS T) have been isolated in some of LD and SD plants, molecular mechanisms underlying the DN-type of the photoperiodic flowering in tomatoes have been remained unknown (Mizoguchi et al. 2007 , this issue). Recently, it has been shown that a FT homolog of tomato has a similar important role in flowering to that of Arabidopsis FT (Lifschitz and Eshed 2006). Do the $G I$ and $C O$ homologs affect the expression of FT homolog in tomato (Figure 3F)? If not, what is a main difference in the GI-CO-FT pathway between the DN plant, tomato, and the LD plant, Arabidopsis? How is expression of the FT homolog gene regulated? To 
isolate Micro-Tom mutants with delayed or accelerated flowering phenotypes and to identify genes responsible for these phenotypes will be crucial steps for the comparison of mechanisms underlying three classes of the photoperiodic flowering responses in plants. The Micro-Tom mutant populations generated by EMSmutagenesis (Watanabe et al. 2007, this issue) and $\gamma$-ray irradiation (Matsukura et al. 2007, this issue) will be useful to screen mutants with altered flowering time, photoperiodic flowering response, and circadian rhythms.

\section{Acknowledgements}

This work was supported in part by a grant from the PROBRAIN (to T.M.).

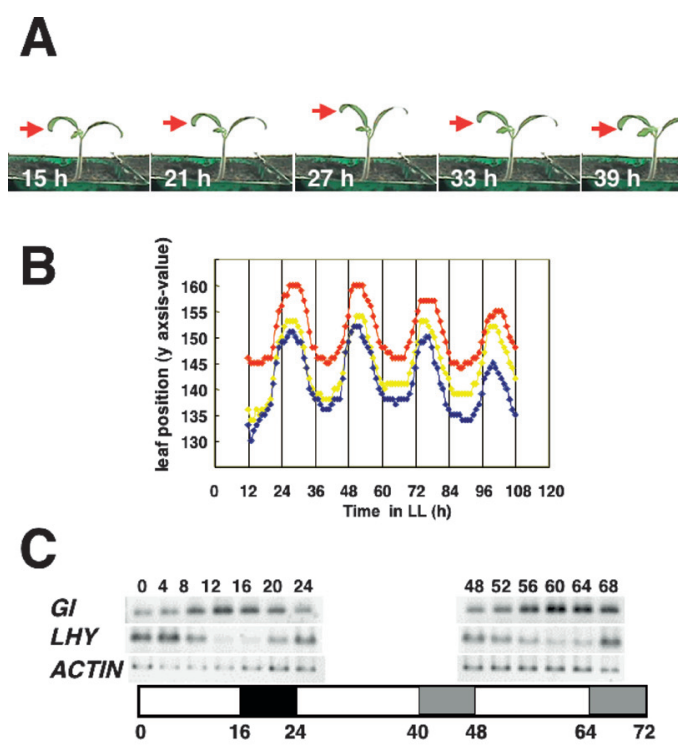

D

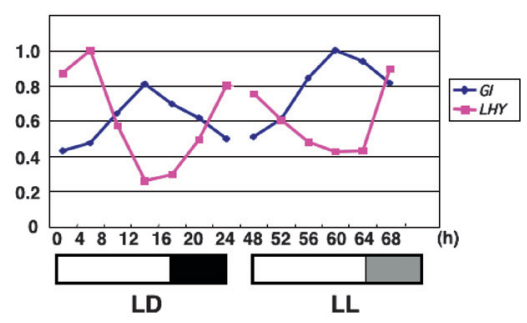

E
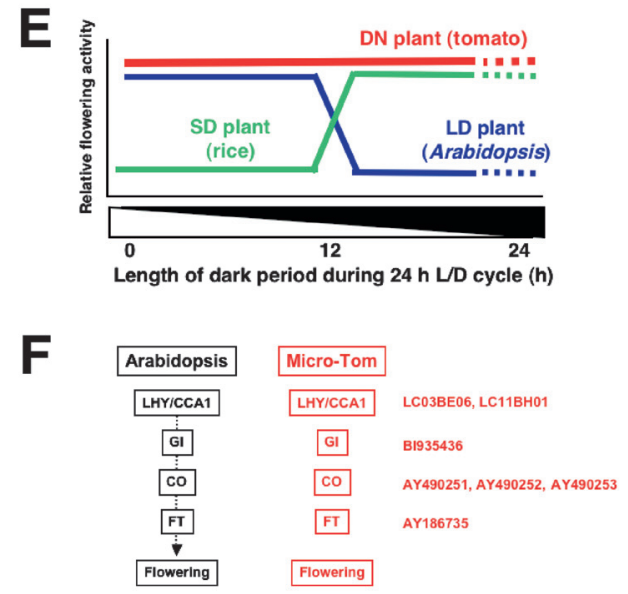

\section{References}

Alabadi D, Oyama T, Yanovsky MJ, Harmon FG, Mas P, Kay SA (2001) Reciprocal regulation between TOC1 and LHY/CCA1 within the Arabidopsis circadian clock. Science 293: 880-883

An H, Roussot C, Suárez-López P, Corbesier L, Vincent C, Piñeiro M, Hepworth S, Mouradov A, Justin S, Turnbull C, Coupland G (2004) CONSTANS acts in the phloem to regulate a systemic signal that induces photoperiodic flowering of Arabidopsis. Development 131: 3615-3626

Anderson SL, Somers DE, Millar AJ, Hanson K, Chory J, Kay SA (1997) Attenuation of phytochrome A and B signaling pathways by the Arabidopsis circadian clock. Plant Cell 9: 1727-1743

Appleby JL, Parkinson JS, Bourret RB (1996) Signal transduction via the multi-step phosphorelay: not necessarily a road less traveled. Cell 86: 845-848

Baillaud L (1962) Mouvements autonomes des tiges, vrilles et autres organes, à l'fexception des organes volubiles et des feuilles. Handbuch der Pflanzenphysiologie 17: 562-634

Barak S, Tobin EM, Andronis C, Sugano S, Green RM (2000) All in good time: the Arabidopsis circadian clock. Trends Plant Sci 5: $517-522$

Blazquez MA, Green R, Nilsson O, Sussman MR, Weigel D (1998) Gibberellins promote flowering of Arabidopsis by activating the LEAFY promoter. Plant Cell 10: 791-800

Borner R, Kampmann G, Chandler J, Gleibner R, Wisman E, Apel $\mathrm{K}$, Melzer S (2000) A MADS domain gene involved in the transition to flowering in Arabidopsis. Plant J 24: 591-599

Bourret RB, Borvich KA, Simon MI (1991) Signal transduction pathways involving protein phosphorylation in prokaryotes. Annu Rev Biochem 60: 401-441

Bradley D, Ratcliffe O, Vincent C, Carpenter R, Coen E (1997) Inflorescence commitment and architecture in Arabidopsis. Science 275: 80-83

Brown AH (1993) Circumnutation: from Darwin to space flights. Plant Physiol 101: 345-348

Calvino M, Kamada H, Mizoguchi T (2005) Is the role of the short-day solely to switch off the CONSTANS in Arabidopsis? Plant Biotechnol 22: 179-183

Carpenter CD, Kreps JA, Simon A (1994) Genes encoding glycinerich Arabidopsis thaliana proteins with RNA-binding motifs are

Figure 3. Circadian rhythms of Micro-Tom. (A) Circadian rhythms of leaf angle in sequence of images of a wild-type seedling (Micro-Tom) under LL. Time in LL is shown. Positions of the leaf tip (red arrows) were monitored every 6 hours as shown in Figure 2(B). (B) Circadian rhythms of leaf angles of three tomato seedlings under LL. The position of the leaf tip and hypocotyls apex was derived as described in Figure 2. Leaf movements were calculated as the vertical distance between the hypocotyl apex and the leaf tips. (C) The expression of the Micro-Tom LHY (LC03BE06/LC11BH01) and GI (B1935436) homologs and actin $(A C T)$ genes was analyzed by RT-PCR in Micro-Tom plants grown in LD (16 h light $/ 8 \mathrm{~h}$ dark) and LL. (D) Results are presented as a proportion of the highest value after standardization with respect to $A C T$ levels. Open and filled bars along the horizontal axis under LD represent light and dark periods, respectively. These are measured in hours from dawn (zeitgeber time; ZT). Open and gray bars along the horizontal axis under LL represent subjective day and subjective night periods, respectively. (E) A schematic model showing the day-length responses of Arabidopsis (LD plant), rice (SD plant) and tomato (Micro-Tom; DN plant) are represented in blue, green and red, respectively. (F) Tomato homologs of $L H Y / C C A 1, G I, C O$ and $F T$ that play key roles in the photoperiodic flowering in Arabidopsis (ref). Accession numbers of the tomato genes are shown. 
influenced by cold treatment and an endogenous circadian rhythm. Plant Physiol 104: 1015-1025

Caré AF, Nefedev L, Bonnet B, Millet B, Badot PM (1998) Cell elongation and revolving movement in Phaseolus vulgaris $\mathrm{L}$. twinning shoots. Plant Cell Physiol 39: 914-921

Chory J, Reinecke, D, Sim, S, Washburn T, Brenner M (1994) A role for cytokinins in de-etiolation in Arabidopsis (det mutants have an altered response to cytokinins). Plant Physiol 104: 339-347

Coté GC (1995) Signal transduction in leaf movement. Plant Physiol 109: 729-734

Covington MF, Panda S, Liu XL, Strayer CA, Wagner DR, Kay SA (2001) ELF3 modulates resetting of the circadian clock in Arabidopsis. Plant Cell 13: 1305-1315

Creelman RA, Mullet JE (1997) Biosynthesis and action of jasmonates in plants. Annu Rev Plant Physiol Plant Mol Biol 48: $355-381$

Darwin C, Darwin F (1880) The Power of Movement in Plants. John Murray, London

de Mairan JJ (1729) Observation botanique. Histoire de l'Académie Royale des Sciences Paris 35-36

Devlin PF, Kay SA (2001) Circadian photoreception. Annu Rev Physiol 63: 677-694

Dodd AN, Love J, Webb AA (2005a) The plant clock shows its metal: circadian regulation of cytosolic free $\mathrm{Ca}(2+)$. Trends Plant Sci 10: 15-21

Dodd AN, Salathia N, Hall A, Kevei E, Toth R, Nagy F, Hibberd JM, Millar AJ, Webb AA (2005b) Plant circadian clocks increase photosynthesis, growth, survival, and competitive advantage. Science 309: 630-633

Dowson-Day MJ, Millar AJ (1999) Circadian dysfunction causes aberrant hypocotyls elongation patterns in Arabidopsis. Plant $J$ 17: 63-71

Doyle MR, Davis SJ, Bastow RM, McWatters HG, Kozma-Bognar L, Nagy F, Millar AJ, Amasino RM (2002) The ELF4 gene controls circadian rhythms and flowering time in Arabidopsis thaliana. Nature 419: 74-77

Dunlap JC (1999) Molecular bases for circadian clocks. Cell 96: 271-290

Engelmann W, Johnsson A (1998) Rhythms in organ movement. In: Lumsden PJ, Millar AJ (eds) Biological rhythms and photoperiodism in plants. Oxford, UK, pp 35-50

Engelmann W, Simon K and Phen CJ (1992) Leaf movement rhythm in Arabidopsis thaliana. Z Naturforsch 47: 925-928

Fowler S, Lee K, Onouchi H, Samach A, Richardson K, Morris B, Coupland G, Putteril J (1999) GIGANTEA: a circadian clockcontrolled gene that regulates photoperiodic flowering in Arabidopsis and encodes a protein with several possible membrane-spanning domains. EMBO J 18: 4679-4688

Gendreau E, Traas J, Desnos T, Grandjean O, Caboche M, Hofte H (1997) Cellular basis of hypocotyls growth in Arabidopsis thaliana. Plant Physiol 114: 295-305

Green RM, Tobin EM (1999) Loss of the circadian clock associated protein 1 in Arabidopsis results in altered clockregulated gene expression. Proc Natl Acad Sci USA 96: 4176-4179

Hangarter RP, Good NE (1981) Evidence that IAA conjugates are slow-release sources of free IAA in plant tissues. Plant Physiol 68: $1424-1427$

Harmer SL, Hogenesch JB, Straume M, Chang HS, Han B, Zhu T, Wang X, Kreps JA, Kay SA (2000) Orchestrated transcription of key pathways in Arabidopsis by the circadian clock. Science
290: $2110-2113$

Hayama R, Coupland G (2003) Shedding light on the circadian clock and the photoperiodic control of flowering. Curr Opin Plant Biol 6: 13-19

Hayama R, Coupland G (2004) The molecular basis of diversity in the photoperiodic flowering responses of Arabidopsis and rice. Plant Physiol 135: 677-684

Hazen SP, Schultz TF, Pruneda-Paz JL, Borevitz JO, Ecker JR, Kay SA (2005) LUX ARRHYTHMO encodes a Myb domain protein essential for circadian rhythms. Proc Natl Acad Sci USA 19: 10387-10392

Hepworth SR, Valverde F, Ravenscroft D, Mouradov A, Coupland G (2002) Antagonistic regulation of flowering-time gene SOC1 by CONSTANS and FLC via separate promoter motifs. EMBO J 21: 4327-4337

Hicks KA, Millar AJ, Carré IA, Somers DE, Straume M, MeeksWargner DR, Kay SA (1996) Conditional circadian dysfunction of the Arabidopsis early-flowering 3 mutant. Science 274: 790-792

Jouve L, Gaspar T, Kevers C, Greppin H, Agosti RD (1999) Involvement of indole-3-aceticacidinthe circadian growth of the first internode of Arabidopsis. Planta 209: 136-142

Jouve L, Greppin H, Agosti RD (1998) Arabidopsis thaliana floral stem elongation: evidence for an endogenous circadian rhythm. Plant Physiol Biochem 36: 469-472

Kardailsky I, Shukla VK, Ahn JH, Dagenais N, Christensen SK, Nguyen JT, Chory J, Harrison MJ, Weigel D (1999) Activation tagging of the floral inducer FT. Science 286: 1962-1965

Kende H and Zeevaart J (1997) The five "classical" plant hormones. Plant Cell 9: 1197-1210

Kim HY, Cote CG, Crain RC (1992) Effects of light on the membrane potential of protoplasts from Samanea saman pulvini: Involvement of the $\mathrm{H}^{+}$-ATPase and $\mathrm{K}^{+}$channels. Plant Physiol 1532-1539

Kim HY, Cote CG, Crain RC (1993) Potassium channels in Samanea saman protoplasts controlled by phytochrome and the biological clock. Science 260: 960-962

Kiyosawa K (1979) Unequal distribution of potassium and anions with in the Phaseolus pulvinus during circadian leaf movement. Plant Cell Physiol 20: 1621-1634

Kleczkowski K, Schell J (1995) Phytohormones conjugates: nature and function. Crit Rev Plant Sci 14: 283-298

Kobayashi Y, Kaya H, Goto K, Iwabuchi M, Araki T (1999) A pair of related genes with antagonistic roles in mediating flowering signals. Science 286: 1960-1962

Koornneef M, Alonso-Blanco C, Blankestijn-de Vries H, Hanhart CJ, Peeters AJ (1998) Genetic interactions among late-flowering mutants of Arabidopsis. Genetics 148: 885-892

Koornneef M, Alonso-Blanco C, Peeters AJM, Soppe W (1998) Genetic control of flowering time in Arabidopsis. Annu Rev Plant Biol 49: 345-370

Koornneef M, Hanhart CJ, Van der Veen JH (1991) A genetic and physiological analysis of late flowering mutants in Arabidopsis thaliana. Mol Gen Genet 229: 57-66

Kotake T, Takada S, Nakahigashi K, Ohto M, Goto K (2003) Arabidopsis TERMINAL FLOWER 2 gene encodes a heterochromatin protein 1 homolog and represses both FLOWERING LOCUS $T$ to regulate flowering time and several floral homeotic genes. Plant Cell Physiol 44: 555-564

Lecharny A, Tremolieres A, Wagner E (1990) Correlation between the endogenous circadian rhythmicity in growth rate and fluctuation in oleic acid content in expanding stems in 
Chenopodium rubrum L. Planta 182: 211-215

Ledger S, Strayer C, Ashton F, Kay SA, Putterill J (2001) Analysis of the function of two circadian-regulated CONSTANS-LIKE genes. Plant J 26: 15-22

Lee H, Suh S-S, Park E, Cho E, Ahn JH, Kim S-G, Lee JS, Kwon YM, Lee I (2000) The AGAMOUS-LIKE 20 MADS domain protein integrates floral inductive pathways in Arabidopsis. Genes Dev 14: 2366-2376

Lidder P, Gutierrez RA, Salome PA, McClung CR, Green PJ (2005) Circadian control of messenger RNA stability: Association with a sequence-specific messenger RNA decay pathway. Plant Physiol 138: 2374-2385

Lifschitz E, Eshed Y (2006) Universal florigenic signals triggered by $F T$ homologues regulate growth and flowering cycles in perennial day-neutral tomato. J Exp Bot 57: 3405-3414

Liu XL, Covington MF, Fankhauser C, Chory J, Wagner DR (2001) ELF3 encodes a circadian clock-regulated nuclear protein that functions in an Arabidopsis PHYB signal transduction pathway. Plant Cell 13: 1293-1304

Locke JC, Southern MM, Kozma-Bognar L, Hibberd V, Brown PE, Turner MS, Millar AJ (2005) Extension of a genetic network model by iterative experimentation and mathematical analysis. Mol Syst Biol 1: E1-E9

Locke JC, Kozma-Bognar L, Gould PD, Feher B, Kevei E, Nagy F, Turner MS, Hall A, Millar AJ (2006) Experimental validation of a predicted feedback loop in the multi-oscillator clock of Arabidopsis thaliana. Mol Syst Biol 2: 59

Lowen CZ, Satter RL (1989) Light-promoted changes in apoplastic $\mathrm{K}^{+}$activity in the Samanea saman pulvinus, monitored with liquid membrane microelectrodes. Planta 179: 421-427

Lu Y, Gehan JP, Sharkey TD (2005) Daylength and circadian effects on starch degradation and maltose metabolism. Plant Physiol 138: 2280-2291

Lubkin S (1994) Unidirect ional waves on Rings: Models for chiral preference of circumnutating plants. Bull Math Biol 56: $795-810$

Mas P, Alabadi, D, Yanovsky MJ, Oyama T, Kay S (2002) Dual role of TOC1 in the control of circadian and photomorphogenic responses in Arabidopsis. Plant Cell 15: 223-236

Matsushika A, Imamura A, Yamashino T, Mizuno T. (2002) Aberrant expression of the light-inducible and circadianregulated APRR 9 gene belonging to the circadian-associated TOC1 quintet results in the phenotype of early flowering in Arabidopsis thaliana. Plant Cell Physiol 43: 833-843

Matsushika A, Makino S, Kojima M, Mizuno T (2000) Circadian waves of expression of the APRR1/TOC1 family of pseudoresponse regulators: Insight into the plant circadian clock in Arabidopsis thaliana. Plant Cell Physiol 41: 1002-1012

Mayer WE, Fischer C (1994) Protoplasts from Phaseolus coccineus L. pulvinar motor cells show circadian volume oscillations. Chronobiol Int 3: 156-164

McGrath RB, Ecker JR (1998) Ethylene signaling: from the membrane to the nucleus. Plant Physiol Biochem 36: 103-113

McWatters HG, Bastow RM, Hall A, Millar AJ (2000) The ELF3 zeitnehmer regulates light signalling to the circadian clock. Nature 408: 716-720

Melin D (1975a) Croissance et mouvements revolutif des tiges de Periploca graeca L. Z Pflanzenphysiol 76: 384-399

Melin D (1975b) Acides aminés libres, port et activité révoltive de rameaux du Periploca graeca L. Planta 125: 105-114

Michael TP, Salome PA, Yu HJ, Spencer TR, Sharp EL, McPeek MA, Alonso JM, Ecker JR, McClung CR (2003) Enhanced fitness conferred by naturally occurring variation in the circadian clock. Science 302: 1049-1053

Michaels SD, Himelblau E, Kim SY, Schomburg FM, Amasino RM (2005) Integration of flowering signals in winter-annual Arabidopsis. Plant Physiol 137: 149-156

Millar AJ, Carré IA, Strayer CA, Chua NH, Kay SA (1995) Circadian clock mutants in Arabidopsis identified by luciferase imaging. Science 267: 1161-1163

Millar AJ, Kay SA (1991) Circadian control of cab gene transcription and mRNA accumulation in Arabidopsis. Plant Cell 3: 541-550

Millet B, Melin D, Badot PM (1988) Circumnutation in Phaseolus vulgaris L. I Growth, osmotic potential and cellular structure in the free-moving part of the shoot. Physiol Plant 72: 133-138

Mizoguchi T, Wheatley K, Hanzawa Y, Wright L, Mizoguchi M, Song HR, Carré IA, Coupland G (2002) LHY and CCA1 are partially redundant genes required to maintain circadian rhythms in Arabidopsis. Dev Cell 2: 629-641

Mizoguchi T, Wright L, Fujiwara S, Cremer F, Lee K, Onouchi H, Mouradov A, Fowler S, Kamada H, Putterill J, Coupland G (2005) Distinct roles of GIGANTEA in promoting flowering and regulating circadian rhythms in Arabidopsis. Plant Cell 17: 2255-2270

Mizoguchi T, Putterill J, Ohkoshi Y (2006) Kinase and phosphatase: the $\operatorname{cog}$ and spring of the circadian clock. Int Rev Cyt 250: 47-72

Mizoguchi T, Niinuma K, Yoshida R (2007) Day-neutral response of photoperiodic flowering in tomatoes: possible implications based on recent molecular genetics of Arabidopsis and rice. Plant Biotechnol 24: 83-86

Mizuno T (1998) His-Asp phosphotransfer signal transduction. $J$ Biochem 123: 555-563

Moon J, Suh S-S, Lee H, Choi K-R, Hong CB, Paek N-C, Kim SG, Lee I (2003) The SOC1 MADS-box gene integrates vernalization and gibberellin signals for flowering in Arabidopsis. Plant J35: 613-623

Moshelion M, Becker D, Biela A, Uehlein N, Hedrich R, Otto B, Levi H, Moran N, Kaldenhoff R (2002a) Plasma membrane aquaporins in the motor cells of Samanea saman: diurnal and circadian regulation. Plant Cell 14: 727-739

Moshelion M, Becker D, Czzempinski K, Mueller-Roeber B, Attali B, Hedrich R, Moran N (2002b) Diurnal and circadian regulation of putative potassium channels in a leaf moving organ. Plant Physiol 128: 634-642

Mouradov A, Cremer F, Coupland G (2002) Control of flowering time: interacting pathways as a basis for diversity. Plant Cell Supplement: S111-S130

Nakamichi N, Kita M, Ito S, Yamashino T, Mizuno T (2005) PSEUDO-RESPONSE REGULATORS, PRR9, PRR7 and PRR5, together play essential roles close to the circadian clock of Arabidopsis thaliana. Plant Cell Physiol 46: 686-698

Niinuma K, Someya N, Kimura M, Yamaguchi I, Hamamoto H (2005) Circadian rhythm of circumnutation in inflorescence stems of Arabidopsis. Plant Cell Physiol 46: 1423-1427

Ohshima S, Murata M, Sakamoto W, Ogura Y, Motoyoshi F (1997) Cloning and molecular analysis of the Arabidopsis gene Terminal Flower 1. Mol Gen Genet 254: 186-194

Onai K, Ishiura M (2005) PHYTOCLOCK 1 encoding a novel GARP protein essential for the Arabidopsis circadian clock. Genes to Cells 10: 963-972

Onouchi H, Igeño MI, Périlleux C, Kathryn G, Coupland G (2000) Mutagenesis of plants overexpressing CONSTANS demonstrates 
novel interactions among Arabidopsis flowering-time genes. Plant Cell 12: 885-900

Park DH, Somers DE, Kim YS, Choy YH, Lim HK, Soh MS, Kim HJ, Kay SA, Nam HG (1999) Control of circadian rhythms and photoperiodic flowering by the Arabidopsis GIGANTEA gene. Science 285: 1579-1582

Parkinson JS, Kofoid EC (1992) Communication modules in bacterial signaling proteins. Annu Rev Genet 26: 71-112

Poethig RS, Sussez IM (1985) The cellular parameters of leaf development in tobacco: a clonal analysis. Planta 165: 170-184

Putterill J, Robson F, Lee K, Simon R, Coupland G (1995) The CONSTANS gene of Arabidopsis promotes flowering and encodes a protein showing similarities to zinc finger transcription factors. Cell 80: 847-857

Ray PM, Alexander WE (1966) Photoperiodic adaptation to latitude in Xanthium strumatium. Amer J Bot 53: 806-819

Salome PA, McClung CR (2004) The Arabidopsis thaliana clock. J Biol Rhythms 19: 425-435

Samach A, Onouchi H, Gold SE, Ditta GS, Schwarz-Sommer Z, Yanofsky MF, Coupland G (2000) Distinct roles of CONSTANS target genes in reproductive development of Arabidopsis. Science 288: 1613-1616

Samach A and Lotan H (2007) The transition to flowering in tomato. Plant Biotechnol 24: 00-00

Satter RL, Galston AW (1981) Mechanisms of control of leaf movements. Annu Rev Plant Physiol 32: 83-110

Satter RL, Geballe GT, Applewhite PB, Galston AW (1974) Potassium flux and leaf movement in Samanea saman: I Rhythmic movement. J Gen Physiol 64: 413-430

Satter RL, Morse MJ (1990) Light-modulated, circadian rhythmic leaf movements in nyctinastic legumes. The Pulvinus: Motor Organ for Leaf Movement. American Society of Plant Physiologists, Rockville, MD, pp 10-24

Satter RL, Morse MJ, Lee Y, Crain RC, Cote G, Moran N (1988) Light and clock-controlled leaflet movements in Samanea saman: a physiological, biophysical and biochemical analysis. Bot Acta 101: 205-213

Schaffer R, Ramsay N, Samach A, Corden S, Putterill J, Carre IA, Coupland G (1998) The late elongated hypocotyl mutation of Arabidopsis disrupts circadian rhythms and the photoperiodic control of flowering. Cell 93: 1219-1229

Searle I, Coupland G (2004) Induction of flowering by seasonal changes in photoperiod. EMBO J 23: 1217-1222

Shuster J, Engelmann W (1997) Circumnutations of Arabidopsis thaliana seedlings. Biol Rhythm Res 28: 422-440

Siefritz F, Otto B, Bienert GP, van der Krol A, Kaldenhoff R (2004) The plasma membrane aquaporin NtAQP1 is a key component of the leaf unfolding mechanism in tobacco. Plant $J$ 37: $147-155$

Simon R, Igeno MI, Coupland G (1996) Activation of floral meristem identity genes in Arabidopsis. Nature 384: 59-62

Simpson GG, Dean C (2002) Arabidopsis, the rosetta stone of flowering time? Science 296: 285-289

Somers DE, Schultz TF, Milnamow M, Kay SA (2000) ZEITLUPE encodes a novel clock-associated PAS protein from Arabidopsis. Cell 101: 319-329

Somers DE, Webb AA, Pearson M, Kay SA (1998) The shortperiod mutant, toc1-1, alters circadian clock regulation of multiple outputs throughout development in Arabidopsis thaliana. Development 125: 485-494

Someya N, Niinuma K, Kimura M, Yamaguchi I, Hamamoto, H (2006) Circumnutation of Arabidopsis thaliana inflorescence stems. Biol Plant 50: 287-290

Strayer C, Oyama T, Schultz TF, Raman R, Somers DE, Mas P, Panda S, Kreps JA, Kay SA (2000) Cloning of the Arabidopsis clock gene TOC1, an autoregulatory response regulator homolog. Science 289: 768-771

Suh S, Moran N, Lee Y (2000) Blue light activates potassiumefflux channels in flexor cells from Samanea saman: motor organs via two mechanisms. Plant Physiol 123: 833-844

Swarup K, Alonso-Blanco C, Lynn JR, Michaels SD, Amasino RM, Koornneef M, Millar AJ (1999) Natural allelic variation identifies new genes in the Arabidopsis circadian system. Plant J 20: 67-77

Swarup K, Alonso-Blanco C, Lynn JR, Michaels SD, Amasino RM, Sun TP, Kamiya Y (1994) The Arabidopsis gal locus encodes the cyclase ent-kaurene synthetase-A of gibberellin biosynthesis. Plant Cell 6: 1509-1518

Súarez-López P, Wheatley K, Robson F, Onouchi H, Valverde F, Coupland G (2001) CONSTANS mediates between the circadian clock and the control of flowering in Arabidopsis. Nature 410: $1116-1120$

Thain SC, Vandenbussche F, Laarhoven LJ, Dowson-Day MJ, Wang ZY, Tobin EM, Harren FJ, Millar AJ, Van Der Straeten D (2004) Circadian rhythms of ethylene emission in Arabidopsis. Plant Physiol 136: 3751-3761

Tseng T-S, Salome PA, McClung CR, Olszewski NE (2004) SPINDLY and GIGANTEA interact and act in Arabidopsis thaliana pathways involved in light responses, flowering, and rhythms in cotyledon movements. Plant Cell 16: 1550-1563

Valverde F, Mouradov A, Soppe W, Ravenscroft D, Samach A, Coupland G (2004) Photoreceptor regulation of CONSTANS protein in photoperiodic flowering. Science 303: 1003-1006

Vanden Dressche T (2000) Nutations in shoots and in Desmodium lateral leaflets, nyctinastism and seismonastism in Mimosa pudica: Comparison and evolution of morphology and mechanism. Biol Rhythm Res 31: 451-468

Wang ZY, Tobin EM (1998) Constitutive expression of the CIRCADIAN CLOCK ASSOCIATED 1 (CCA1) gene disrupts circadian rhythms and suppresses its own expression. Cell 93: $1207-1217$

Wilson RN, Heckman JW, Somerville CR (1992) Gibberellin is required for flowering in Arabidopsis thaliana under short days. Plant Physiol 100: 403-408

Yamaguchi A, Kobayashi Y, Goto K, Abe M, Araki T (2005) TWIN SISTER OF FT (TSF) acts as a floral pathway integrator redundantly with FT. Plant Cell Physiol 46: 1175-1189

Yanovsky MJ, Kay SA (2002) Molecular basis of seasonal time measurement in Arabidopsis. Nature 419: 308-312

Yanovsky MJ, Kay SA (2003) Living by the calendar: how plants know when to flower. Nature Rev Mol Cell Biol 4: 265-275

Zagotta MT, Hicks KA, Jacobs CI, Young JC, Hangarter RP and Meeks-Wagner DR (1996) The Arabidopsis ELF3 gene regulates vegetative photomorphogenesis and the photoperiodic induction of flowering. Plant J 10: 691-702

Zeilinger MN, Farre EM, Taylor SR, Kay SA, Doyle FJ 3rd (2006) A novel computational model of the circadian clock in Arabidopsis that incorporates PRR7 and PRR9. Mol Syst Biol 2: 58 